DOI: https://doi.org/10.33103/uot.ijccce.20.2.7

\title{
Robust Controller Design for Flexible Joint Based on Back-Stepping Approach
}

\author{
Ahmed Mohsen Mohammad ${ }^{1}$, Shibly Ahmed AL-Samarraie ${ }^{2}$ \\ ${ }^{1,2}$ University of Technology, Control and Systems Department, Baghdad, Iraq \\ 61457@student.uotechnology.edu.iq,60132@uotechnology.edu.iq
}

\begin{abstract}
The objective of this paper is to design a robust controller for a system modeled as a two-mass system, with a flexible coupling. Here, the flexible Joint between two-mass systems is characterized by a spring. In fact, a two-mass system represents most of an industrial drive, like rolling mill drives, automated arms, conveyor belts, and so on, that has a flexible joint, for which oscillation suppression and robust control against model uncertainties and external disturbances are very important. The proposed controller is based on sliding mode control with a back-stepping approach. Two subsystems (upper and lower) strategies are proposed for two- mass systems. On this basis, the classical sliding mode controller for each subsystem based on Lyapunov stability theory and sliding mode control theory is addressed to eliminate the influences of the parametric uncertainties, nonlinearities, and external disturbance load with the aid of sliding mode perturbation observer. Finally, comprehensive simulations are conducted to demonstrate the excellent performance of the proposed method.
\end{abstract}

Index Terms-Two-mass system, Flexible joint, Sliding Mode Control, Back-stepping approach.

\section{INTRODUCTION}

The drive and the load in many industrial applications are connected by a coupling shaft which cannot be modeled completely by a rigid body, such as steel rolling mills drives, flexible robot arms, conveyor belts. In many cases of the above applications, the process can be characterized as elastic coupled two-mass systems. If the coupling is not stiff enough in two-mass systems, various vibrations are caused by a torsional torque. Flexible joints lead to elastic torsion, thus, the two-mass systems have the tendency to swing [1].

In various applications such as robots, machine tools, systems, electric driving systems with flexible joints are widely used. Due to the flexible joint, non-linear friction, and backlash, the dynamic performances of speed and the position-controlled multi-mass driving system can deteriorate [1]. These vibrations need to be suppressed actively, therefore; this can be a problem for standard classical control strategies.

Many methods have been used to control the speed or position in order to achieve good performance. One of the most popular control methods in the rotary positioning systems or speed control is a PID controller, the tasks for the control of the two-mass resonant system suppress the shaft torsional vibration, reject the external load disturbance and tracking the speed of load to the speed of reference without overshoot are proposed in [2-4]. For adjusting the feedback gains of the PID controller for predesigned load inertia, there are many gain tuning methods of PID control as given in $[5,6]$.

As well, in spite of the existence of the nonlinearities between the motor and the load, also without using the motor side sensing element, semi-dual loop control designed with luenberger state observer to feedback the motor side velocity was presented by [7] to improve the positioning performance.

The adaptive back-stepping control in [8] is proposed to overcome systems with nonlinear stiffness. As well as the friction torques on the end of the shaft are considered. So, 
this controller is able to remove the shaft oscillations and to compensate for the nonlinear friction with the presence of unknown parameters.

Another different concept to test and evaluate the torsional vibration suppression in the two-mass system is used in [9] based on the model reference adaptive system with a fuzzyneural controller and one basic feedback from easily measured motor speed. Neural Networks (NNs) based speed estimation is proposed in[9] for the uncommon sort of the drive system with a flexible association between the determined motor and load.

Robust tracking and vibration suppression for a two-mass system are proposed in [10] which is combining between two controllers, one controller designed by the back-stepping approach for the outer loop and the other controller designed by the new partial disturbance observer (DOB)for the inner loop. On the other hand in [11], the adaptive robust control (ARC) has a better tracking performance and transient in the presence of discontinuous disturbances, such as friction, and it is of a lower order compared with disturbance observer (DOB).

Disturbance observer which is added to the Kalman filter in order to have robustness against the system errors and motion controller were proposed in [12] to improve the robustness of the system. As well the motion controller is robust to the disturbance and the parameter variations. A common nonlinear control design by means of exact linearization has been proposed in [13].

When the load is connected to the driving motor by a long shaft, a finite and small elasticity of the shaft gets magnified and has a vibrational influence on the load speed. This vibration is not only undesirable but also the origin of the instability of the system in some cases. Imperfect derivative feedback of the estimated torsional torque controller is proposed [14], where this controller consists of three simple elements: the disturbance observer, the imperfect derivative filter, and the feedback gain.

A classical control structure of sliding mode control using a two-mass drive system has the chattering phenomenon seems to be a big obstacle. In order to eliminate this phenomenon, and to improve the characteristics of the performance of the system, investigating an integral sliding mode control(ISMC) with an adaptive low pass filter (LPF) as proposed[15]. The observer-based discrete-time sliding mode (ODSM) control implementation for a two-mass system coupled with a flexible shaft to speed control is proposed by [16].

As the studies showed, the SMC guarantee insensitivity to parametric variation and external disturbances. Due to this, it a very attractive control method, because it meets modern, high requirements.But unfortunately, such a control method has a phenomenon namely - the chattering effect. This phenomenon may cause damage to system components. However, due to the characteristic of the SMC, many efforts have been made to minimize or eliminate the chattering. In addition to the SMC is developing by many scientists, who have been trying to implement it in many advanced, practical applications working in difficult environments such as a steered-by-wire road vehicle [17-24].

In the present work, the SMC theory-based backstepping approach will be utilized to design a robust controller that makes the position of the load part of the two-mass system follow the desired position with high precision. The proposed controller in this work will use the sliding mode perturbation estimator and the sliding mode differentiator in order to estimate an unknown perturbation and required derivatives in its formula. 


\section{SYSTEM DESCRIPTION AND PROBLEM STATMENET}

Flexible joints are widely used in industrial robotics. This can be seen in many applications especially in flexible robot arms, where the drive and the load are connected by a flexible joint which cannot be modeled completely by a rigid body [1]. The flexibility at a joint can be characterized by a linear, torsional spring as indicated in figure 1.

Inflexible joint robot manipulators, the elasticity of the transmission devices on the joints has been taken into account. Considering the effect of joint flexibility would develop a more exact model of an industrial robot. However, further complexity is added to the robot model, which raises a new control problem and therefore motivated the researchers in this relevant field to further indulge [25].

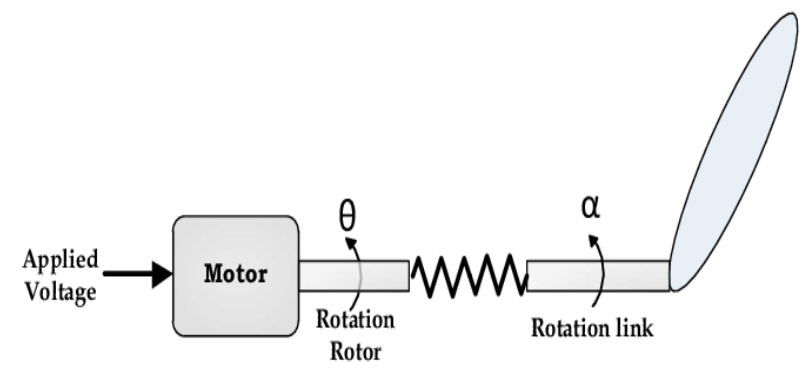

Figure 1: FLEXIBLE JOINT ROBOT.

\section{A. Mathematical model of the system}

A two-mass drive system with an elastic joint is shown in figure .2. This model for the flexible system is considered in this work, which can be described in the per-unit system.

The two-mass resonant system is consisting of two lumped inertias J_mand J_l, representing the motor and load, respectively, which coupled via a shaft of finite stiffness k_s. The first mass represents the load mass while the second mass represents the motor mass. The two-mass system is subject to torsional torque $\mathrm{T}$ _spand excited by a combination of electromagnetic torque $\mathrm{T}$ _m and load torque $\mathrm{T} \_\mathrm{l}$.

Generally, the angular position $\theta \_\mathrm{m}$ and angular velocity $\omega_{-} \mathrm{m}$ of the motor shaft differ from the respective variables $\theta \_1$ and $\omega_{-} 1$ on the load side. The torsional torque equals the load torque only in the steady-state. Table 1 gives a definition of the two-mass system.

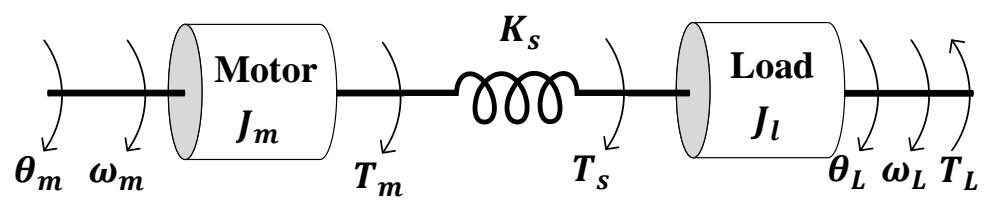

FIGURE 2: TWO-MASS DRIVE SYSTEM

TABLE 1: THE PARAMETERS OF THE TWO-MASS SYSTEM[26]

\begin{tabular}{cc}
\hline Symbol & Quantity \\
\hline$K_{S}$ & shaft stiffness \\
$J_{m}$ & motor inertia \\
$J_{l}$ & load inertia \\
$B_{m}$ & coefficient of motor viscosity \\
$B_{l}$ & coefficient of load viscosity \\
\hline
\end{tabular}

The state equation of two-mass resonant system is as follows[27]: 


$$
\begin{aligned}
J_{m} \ddot{\theta}_{m} & =T_{m}-K_{s}\left(\theta_{m}-\theta_{l}\right)-B_{m} \dot{\theta}_{m} \\
J_{l} \ddot{\theta}_{l} & =K_{s}\left(\theta_{m}-\theta_{l}\right)-B_{l} \dot{\theta}_{l}-T_{L}
\end{aligned}
$$

For the convenience of controller design, the following state variables are defined

$$
\left[\theta_{l}, w_{l}, \theta_{m}, \omega_{m}\right]^{T}=\left[x_{1}, x_{2}, x_{3}, x_{4}\right]^{T}
$$

Also, the motor torque $T_{m}$ is considered here as the control input; so set $T_{m}=u$, thus, the dynamics in (4) and (5) can be rewritten as follows:

$$
\left.\begin{array}{c}
\dot{x}_{1}=x_{2} \\
\dot{x}_{2}=-\frac{K_{s}}{J_{l}} x_{1}-\frac{B_{l}}{J_{l}} x_{2}+\frac{K_{s}}{J_{l}} x_{3}-\frac{1}{J_{l}} T_{L} \\
\dot{x}_{3}=x_{4} \\
\dot{x}_{4}=\frac{K_{s}}{J_{m}} x_{1}-\frac{K_{s}}{J_{m}} x_{3}-\frac{B_{m}}{J_{m}} x_{4}+\frac{1}{J_{m}} u
\end{array}\right\}
$$

Consider the plant dynamics as follows;

$$
\left.\begin{array}{c}
\dot{x}_{1}=x_{2} \\
\dot{x}_{2}=-\frac{K_{S}}{J_{l}} x_{1}-\frac{B_{l}}{J_{l}} x_{2}+\frac{K_{S}}{J_{l}} x_{3}-\frac{1}{J_{l}} T_{L}
\end{array}\right\}
$$

Let $\quad a_{1}=-\frac{K_{S}}{J_{l}}, a_{2}=-\frac{B_{l}}{J_{l}}, b_{1}=\frac{K_{S}}{J_{l}}, d(t)=-\frac{1}{J_{l}} T_{L}$ and $u_{l}=x_{3}$. Equation (4) accordingly becomes;

$$
\left.\begin{array}{c}
\dot{x}_{1}=x_{2} \\
\dot{x}_{2}=a_{1} x_{1}+a_{2} x_{2}+b_{1} u_{l}+d(t)
\end{array}\right\}
$$

The uncertainty in the above equation consists in the stiffness value; i.e., $K_{S}$ can be written as

$$
K_{s}=K_{s n}+\Delta K_{s} \Rightarrow a_{1}=a_{1 n}+\Delta a_{1}, \quad b_{1}=b_{1 n}+\Delta b_{1}
$$

Equation (5) is then written as;

$$
\left.\begin{array}{c}
\dot{x}_{1}=x_{2} \\
\dot{x}_{2}=a_{1 n} x_{1}+a_{2 n} x_{2}+b_{1 n} u_{l}+\delta_{l}(t)
\end{array}\right\}
$$

where $a_{2 n}=a_{2}$, and

$$
\delta_{l}(t)=\Delta a_{1} x_{1}+\Delta b_{1} u_{l}+d(t)
$$

Now, consider the motor dynamics as follows;

$$
\left.\begin{array}{c}
\dot{x}_{3}=x_{4} \\
\dot{x}_{4}=\frac{K_{S}}{J_{m}} x_{1}-\frac{K_{S}}{J_{m}} x_{3}-\frac{B_{m}}{J_{m}} x_{4}+\frac{1}{J_{m}} u
\end{array}\right\}
$$

Let $c_{1}=\frac{K_{s}}{J_{m}}, c_{2}=-\frac{K_{s}}{J_{m}}, \quad c_{3}=-\frac{B_{m}}{J_{m}} a n d b_{2}=\frac{1}{J_{m}}$. Equation (8) accordingly becomes;

$$
\left.\begin{array}{c}
\dot{x}_{3}=x_{4} \\
\dot{x}_{4}=c_{1} x_{1}+c_{2} x_{3}+c_{3} x_{4}+b_{2} u
\end{array}\right\}
$$

As for in Eq. (6), the uncertainty in Eq. (8) consists in the stiffness value; i.e., in $K_{s}$ magnitude and can be written

$$
K_{s}=K_{s n}+\Delta K_{s} \Rightarrow c_{1}=c_{1 n}+\Delta c_{1} \& c_{2}=c_{2 n}+\Delta c_{2}
$$

Equation (9) is then written as;

$$
\left.\begin{array}{c}
\dot{x}_{3}=x_{4} \\
\dot{x}_{4}=c_{1 n} x_{1}+c_{2 n} x_{3}+c_{3 n} x_{4}+b_{2 n} u_{m}+\delta_{m}(t)
\end{array}\right\}
$$

wherec $_{3 n}=c_{3}, b_{2 n}=b_{2}$ and 


$$
\delta_{m}(t)=\Delta c_{1} x_{1}+\Delta c_{2} x_{3}
$$

Note that in Eq. (6) and (10), the subscription refers to the functions with nominal parameters, $\delta \_1$ and $\delta \_\mathrm{m}$ are the terms of the perturbation, which they act on the dynamics of the first and the second mass respectively. The first and the second subsystems are referred to them here as the upper and lower subsystems respectively.

Eventually, from the two-mass system model in Eq. (6) and Eq. (10), the following points can be noted; 1) The two-mass system model is an underactuated mechanical system. That because the system modeled with two degrees of freedom (DOF), but actuated by only one control input (the motor torque). Designing a controller for the underactuated mechanical system is a difficult task since we need to control 2DOF by only one control.

2) The matching condition is not satisfied. That because the control input does not exist in the upper subsystem dynamics (the load mass), which is affected by the perturbation $\delta \_1(\mathrm{t}, \mathrm{x})$.

In this work, a nonlinear controller will be designed using the sliding mode control theory. The sliding mode control will be designed for each degree of freedom separately with the aid of a perturbation observer used to estimate the perturbation term $\delta \_1(\mathrm{t}, \mathrm{x})$ which enables us to solve the matching condition problem. Then using the Back-stepping approach, the control law can be derived. The proposed controller will enforce a desired behavior on the load mass. Using the Back-stepping approach will enable one control input from controlling the two-mass system.

\section{CONTROLLER DESGIN}

\section{A. Sliding Mode Control}

The sliding mode control (SMC) method is recognized as one efficient tool to design a robust controller for complex high-order nonlinear dynamical systems because it has superb characteristics such as insensitivity to large parameter variations; it's operating with the presence of disturbance inputs, and its ability to reject it. These characteristics gained SMC significant interest in recent years and made it a more attractive control method [1]. Unfortunately, this control method has also a phenomenon namely the chattering effect, which may cause a glitch to system components in practical engineering systems.

However, many efforts have been made to minimize the chattering phenomenon. As well as this method is still being developed and implemented in many practical applications such as an underwater vehicle, a steered-by-wire road vehicle[15].

\section{B. Control Design Steps}

In this section, a convenience strategy to design a sliding mode controller will be presented. Firstly, we will divide the system in Eq. (3) into two subsystems; upper and lower subsystems. For each subsystem, the sliding variable is assigned based on the standard or 1st order SMC theory. The objective from the designed controller is to force state trajectories into the level zero for each sliding variable. The loci of the points of the sliding variable level zero are called the sliding manifold or switching surface. After designing the SMC successfully, the state trajectory is directed towards the sliding manifold and then maintained it on this manifold for all future time. As a result, the state moves toward the origin or its neighborhood and stays there for all next time. This behavior is known as the reaching and sliding phases; which are depicted in Figure (3) for a typical second-order system [29]. 


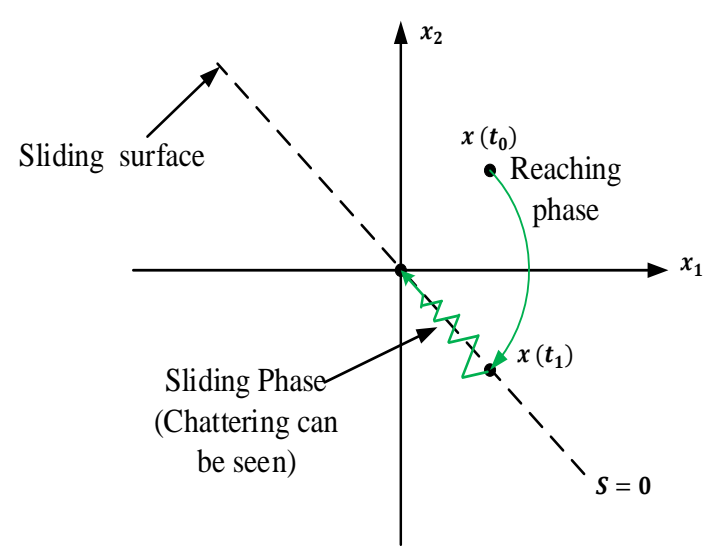

FigURE 3: STATE PLANE OF THE SECOND-ORDER RELAY SYSTEM.

As mentioned above, the SMC is designed for each subsystem; so, for the upper subsystem as in Eq. 6, let

$$
u_{l}=\left(\frac{1}{b_{1 n}}\right)\left(u_{l n}+u_{l s}\right)
$$

where $u_{l n}$ is the nominal control, which will be determined later.For the upper subsystem, the sliding variable $s_{l}$ is defined as

$$
s_{l}=\dot{e}_{l}+\lambda_{l} e_{l}
$$

where $\lambda_{l}>0$ is a design parameter, $e_{l}$ and $\dot{e}_{l}$ are defined as

$$
\left.\begin{array}{c}
e_{l}=x_{1}-x_{1 d} \\
\dot{e}_{l}=x_{2}-\dot{x}_{1 d}
\end{array}\right\}
$$

The nominal control for the upper subsystem is selected as;

$$
u_{l n}=-a_{1 n} x_{1}-a_{2 n} x_{2}+\ddot{x}_{1 d}-\lambda_{1} \dot{e}_{l}-\hat{\delta}_{l}
$$

where $\hat{\delta}_{l}$ is perturbation estimation and it will be determined in the section (4).

The second term in the control law is $u_{l s}$ which it is taken here as

$$
u_{l s}=-k_{l} * s_{l}
$$

The value of $k_{l}$, is determined using the following non-smooth Lyapunov function:

$$
V_{l}=\left|s_{l}\right|
$$

To ensure the attractiveness of the sliding manifold $\left(s_{l}=0\right), k_{l}$ is selected such that the derivative of the Lyapunov function $V_{l}$ is negative definite as can be shown in the following steps;

$$
\left.\begin{array}{c}
\dot{V}_{l}=\operatorname{sgn}\left(s_{l}\right) * \dot{s}_{l} \\
=\operatorname{sgn}\left(s_{l}\right) *\left[a_{1 n} x_{1}+a_{2 n} x_{2}+b_{1 n} u_{l}+\delta_{l}(t)-\ddot{x}_{1 d}+\lambda_{1} \dot{e}_{l}\right]
\end{array}\right\}
$$

After substituting the proposed controller in $\dot{V}_{l}$, we obtained

$$
\left.\begin{array}{c}
\dot{V}_{l}=\operatorname{sgn}\left(s_{l}\right) *\left[a_{1 n} x_{1}+a_{2 n} x_{2}+u_{l n}+u_{l s}+\delta_{l}(t)-\ddot{x}_{1 d}+\lambda_{1} \dot{e}_{l}\right] \\
=\operatorname{sgn}\left(s_{l}\right) *\left[-k_{l} * s_{l}\right] \\
\leq-k_{l} *\left|s_{l}\right|
\end{array}\right\}
$$

So for $k_{l}>0, V_{l}$ decays asymptotically to zero according to the following inequality;

$$
V_{l} \leq V_{l o} e^{-k_{l}\left(t-t_{o}\right)}
$$


Or equivalently the sliding variable $\left|s_{l}\right|$ decays exponentially to zero according to the following inequality;

where $s_{l o}$ is the initial value of $s_{l}$.

$$
\left|s_{l}\right| \leq\left|s_{l o}\right| e^{-k_{l}\left(t-t_{o}\right)}
$$

In a similar way, the following steps are adapted for the lower subsystem which it given in Eq. 10. Let the sliding variable $s_{m}$ be defined as

$$
s_{m}=\dot{e}_{m}+\lambda_{m} e_{m}
$$

where $\lambda_{m}>0$ is a design parameter, $e_{m}$ and $\dot{e}_{m}$ are defined as

$$
\left.\begin{array}{l}
e_{m}=x_{3}-u_{l} \\
\dot{e}_{m}=x_{4}-\dot{u}_{l}
\end{array}\right\}
$$

To this end, the proposed controller for the lower subsystem is given by

$$
u_{m}=\left(\frac{1}{b_{2 n}}\right)\left(u_{m n}+u_{m s}\right)
$$

where $u_{m n}$ is the nominal control for the lower subsystem. It is selected here as follows;

$$
u_{m n}=-c_{1 n} x_{1}-c_{2 n} x_{3}-c_{3 n} x_{4}+\ddot{u}_{l}-\lambda_{2} \dot{e}_{m}
$$

while the control term $u_{m s}$ is selected as follows

$$
u_{m s}=-k_{m} * \operatorname{sign}\left(s_{m}\right)
$$

As for the upper subsystem, the value of $k_{m}$, is determined using the following non-smooth Lyapunov function;

$$
V_{m}=\left|s_{m}\right|
$$

To ensure the attractiveness of the sliding manifold $\left(s_{m}=0\right), k_{m}$ is selected such that the derivative of the Lyapunov function $V_{m}$ is negative definite as can be shown in the following steps;

$$
\begin{gathered}
\dot{V}_{m}=\operatorname{sgn}\left(s_{m}\right) * \dot{s}_{m} \\
=\operatorname{sgn}\left(s_{m}\right) *\left[c_{1 n} x_{1}+c_{2 n} x_{3}+c_{3 n} x_{4}+b_{2 n} u_{m}+\delta_{m}(t)-\ddot{u}_{l}+\lambda_{2} \dot{e}_{m}\right]
\end{gathered}
$$

After substituting the proposed controller in $\dot{V}_{m}$, we obtained

$$
\left.\begin{array}{c}
\dot{V}_{m}=\operatorname{sgn}\left(s_{m}\right) *\left[c_{1 n} x_{1}+c_{2 n} x_{3}+c_{3 n} x_{4}+u_{m n}+u_{m s}+\delta_{m}(t)-\ddot{u}_{l}+\lambda_{2} \dot{e}_{m}\right] \\
=\operatorname{sgn}\left(s_{m}\right) *\left[-k_{m} * \operatorname{sign}\left(s_{m}\right)+\delta_{m}(t)\right] \\
=-k_{m}+\operatorname{sign}\left(s_{m}\right) * \delta_{m}(t) \\
\leq-k_{m}+\left|\delta_{m}(t)\right|
\end{array}\right\}
$$

Then, $\dot{V}_{m}$ is negative definite if $k_{m}$ satisfies the following inequality;

$$
k_{m}>\max \left|\delta_{m}(t, x)\right|=h
$$

When the inequality (27) is satisfied, the error state $\left(e_{m}, \dot{e}_{m}\right)$,reaches $s_{m}=0$ in a finite time. The chattering behavior will appear as a result of using discontinuous control law in Eq. (21).Moreover, the chattering amplitude is related directly to the value of $k_{m}$. So, one solution which used to attenuate chattering is by replacing the discontinuous term in Eq. (21) by a continuous function. In the present work, the discontinuous termsgn $\left(s_{m}\right)$ is replaced by:

$$
\operatorname{sgn}\left(s_{m}\right)=\frac{2}{\pi} \tan ^{-1}\left(q_{m} s_{m}\right), \quad q_{m}>1
$$

Remark 1: the nominal control term for the upper subsystem $u_{l n}$ contains the estimation for the perturbation term $\hat{\delta}_{l}$. The used estimator for $\delta_{l}$ is the sliding mode estimator, which implemented in section (4). As a result, the derivative of the sliding variable $\dot{s}_{l}$ will consist of the control term $u_{l s}$ only. 
For this case, $u_{l s}$ is selected as a linear proportional to the sliding variable $s_{l}$ instead of a discontinuous relation as in the classical SMC. The linear selection leads to an asymptotic reaching to the sliding manifold $\left(s_{l}=0\right)$.

Remark 2: the control law contains the virtual control $u_{l}$ and its first and second derivative $\dot{u}_{l}$ and $\ddot{u}_{l}$ respectively. To provide the control law with $\dot{u}_{l}$ and $\ddot{u}_{l}$, one can compute the first and the second derivatives with time for $u_{l}$. Getting these derivatives will lead to the so-called explosion of terms and make the control law huge[28]. Alternatively, $\dot{u}_{l}$ and $\ddot{u}_{l}$ can be estimated by using an observer such as a sliding mode differentiator (SMD) which proposed in [29]. The details of designing the SMD are in section 4.

Remark 3: Since the virtual control $u_{l s}$ is smooth enough, i.e., differentiable, the control law for the lower subsystem uses its first and second derivatives in Eq. (20) and in Eq. (23) for the sliding variable $s_{m}$ and for the nominal control term $u_{m n}$ respectively

\section{SLIDING MODE PERTURBATION ESTIMATOR (SMPE) AND SLIDING MODE DIFFERENTIATOR (SMD)}

In this section, a SMO based on reference [29], is utilized to estimate the perturbation $\delta_{l}(t)$, via the SMPE, that acts on the first subsystem; also it is used here to estimate the first and the second derivatives of $u_{l}\left(\dot{u}_{l}\right.$ and $\left.\ddot{u}_{l}\right)$ via SMD. The estimated perturbation $\hat{\delta}_{l}(t)$ and the first and the second derivatives of $u_{l}$ are used in the proposed control law in Eq. (22).

Now, we construct the SMPE to estimate $\delta_{l}$ is in Eq. (29):

$$
\left.\begin{array}{c}
s_{o 1}=x_{2}-\hat{x}_{2} \\
\eta_{1}=k_{o 1} * \tan ^{-1}\left(\gamma_{1} s_{o 1}\right) \\
\dot{\hat{x}}_{2}=a_{1 n} x_{1}+a_{2 n} x_{2}+b_{1 n} x_{3}+\eta_{1} \\
\dot{v}_{1}=\frac{1}{\tau_{1}}\left(-v_{1}+k_{o 1} * \tan ^{-1}\left(\gamma_{1} s_{o 1}\right)\right)
\end{array}\right\}
$$

where $s_{o 1}$ is the SMPE variable, and $k_{o 1}$ and $\gamma_{1}$ are the estimator parameter. The SMPE dynamic is proposed in the third line in Eq. (29), and $\eta_{1}$ represents the estimator input. Thus, $v_{1}=\hat{\delta}_{l}$ is the estimated value of the perturbation $\delta_{l}$.

The SMD which are used to obtain the estimation to the first and the second derivatives of $u_{l}\left(\dot{u}_{l}\right.$ and $\ddot{u}_{l}$ ) are presented in Eq. (30) and (31) below respectively

$$
\left.\begin{array}{c}
s_{o 2}=u_{l}-\eta_{2} \\
\dot{\eta}_{2}=k_{o 2} * \tan ^{-1}\left(\gamma_{2} s_{o 2}\right) \\
\dot{v}_{2}=\frac{1}{\tau_{2}}\left(-v_{2}+k_{o 2} * \tan ^{-1}\left(\gamma_{2} s_{o 2}\right)\right)
\end{array}\right\}
$$

and

$$
\left.\begin{array}{c}
s_{o 3}=v_{2}-\eta_{3} \\
\dot{\eta}_{3}=k_{o 3} * \tan ^{-1}\left(\gamma_{3} s_{o 3}\right) \\
\dot{v}_{3}=\frac{1}{\tau_{3}}\left(-v_{3}+k_{o 3} * \tan ^{-1}\left(\gamma_{3} s_{o 3}\right)\right)
\end{array}\right\}
$$

where $s_{O 2}$ and $s_{O 3}$ are the sliding mode differentiator variables, and $k_{O 2}, k_{o 3}, \gamma_{2}$ and $\gamma_{3}$ are the differentiator parameters. The second line in Eq. (30) and Eq. (31) are the SMD dynamics, while the third lines in Eq. (30) and Eq. (31) are the low pass filters with time constants $\tau_{2}$ and $\tau_{3}$ respectively. The outputs of the low pass filters $v_{2}$ and $v_{3}$ are the first and second estimation for the first and second derivatives for $u_{l}$, respectively.

Remark 4: In Eq. (30) and Eq. (31), the SMD parameters are taken as follows;

$$
\tau_{3}=\tau_{2} \text { and } \gamma_{3}=\gamma_{2}
$$




\section{SIMULATIONS RESULT AND DISCUSSIONS}

In this section the results of the numerical simulations for the two mass system connected by flexible joint are presented. The parameters that were used in the simulations are shown in Table 2, while the parameters of SMC and the observers (SMD, SMPE), which are needed in Eq. (19), Eq. (28), Eq. (29), Eq. (30) and Eq. (31) are given in Table 3.

TABLE 2: NOMINAL PARAMETERS OF THE TWO-MASS SYSTEM[4].

\begin{tabular}{|c|c|c|c|c|c|}
\hline Symbol & \multicolumn{2}{|c|}{ Quantity } & \multicolumn{2}{|r|}{ Values } & Unit \\
\hline$K_{s}$ & \multicolumn{2}{|c|}{ shaft stiffness } & \multicolumn{2}{|r|}{30} & $\mathrm{Nm} / \mathrm{rad}$ \\
\hline$J_{m}$ & \multicolumn{2}{|c|}{ motor inertia } & \multicolumn{2}{|r|}{0.02} & $\mathrm{Kg} \cdot \mathrm{m}^{2}$ \\
\hline$J_{l}$ & \multicolumn{2}{|c|}{ load inertia } & \multicolumn{2}{|r|}{0.165} & Kg. $\mathrm{m}^{2}$ \\
\hline$B_{m}$ & \multicolumn{2}{|c|}{ coefficient of motor viscosity } & \multicolumn{2}{|r|}{0.002} & $\mathrm{Nm} / \mathrm{rad} / \mathrm{s}$ \\
\hline$B_{l}$ & \multicolumn{2}{|c|}{ coefficient of load viscosity } & \multicolumn{2}{|r|}{0.007} & $\mathrm{Nm} / \mathrm{rad} / \mathrm{s}$ \\
\hline \multicolumn{6}{|c|}{ TABLE 3: CONTROLLER AND OBSERVER PARAMETERS } \\
\hline $\begin{array}{c}\text { SMC } \\
\text { parameters }\end{array}$ & Value & $\begin{array}{c}\text { SMPE } \\
\text { parameters }\end{array}$ & Value & $\begin{array}{c}\text { SMD } \\
\text { parameters }\end{array}$ & Value \\
\hline$k_{l}$ & 1 & $k_{o 1}$ & 150 & $k_{o 2}=k_{o 3}$ & 100 \\
\hline$\lambda_{l}=\lambda_{m}$ & 25 & $\gamma_{1}$ & 50 & $\gamma_{2}, \gamma_{3}$ & 50 \\
\hline$q_{m}$ & 34 & $\tau_{1}$ & 0.001 & $\tau_{2}=\tau_{3}$ & 0.001 \\
\hline
\end{tabular}

In this work, the main source for the uncertainty is due to the shaft stiffness value, which is ranging from (21-39) Nm/rad. Accordingly, the only uncertain terms are those coefficients in the system model, which contains $K_{S}$. In addition, the external torque that was considered here is $T_{L}=0.35 * \sin (2 \pi * t)$. Table 4 presents the system model coefficients, the maximum bound on their uncertainties, and the maximum bound on the external torque.

TABLE 4: NOMINAL PARAMETERS OF THE TWO-MASS SYSTEM

\begin{tabular}{ccc}
\hline Symbol & Nominal & Uncertainty Bound \\
\hline$a_{1}$ & 181.81 & $\left|\Delta a_{1}\right|<55$ \\
$a_{2}$ & 0.04242 & - \\
$c_{1}$ & 1500 & $\left|\Delta c_{1}\right|<450$ \\
$c_{2}$ & 1500 & $\left|\Delta c_{1}\right|<450$ \\
$c_{3}$ & 0.1 & - \\
$b_{1}$ & 181.81 & $\left|\Delta a_{1}\right|<55$ \\
$b_{2}$ & 50 & - \\
$d$ & - & $|d|<3.03$
\end{tabular}

The gain $k_{m}$ in Eq. (24), which was used in the numerical simulation in this work, is given by

$$
k_{m}=450\left|x_{1}\right|+450\left|x_{3}\right|
$$

Three numerical simulations were done for different desired reference position to the upper subsystem positionx_1d. In the first numerical simulation,K_s $=22 \mathrm{Nm} / \mathrm{rad}$, and the desired reference position is taken as $\mathrm{x}_{-} 1 \mathrm{~d}=\sin :(\mathrm{t})$. The proposed sliding mode controller for the lower subsystems $\mathrm{u}_{-} \mathrm{m}$ will regulate the sliding variable $s \_m$ to the origin after less than $0.06 \mathrm{sec}$. as shown in Fig. (4). After 
that $\mathrm{e} \_\mathrm{m} \rightarrow 0$ asymptotically, and that enforces $\mathrm{x} \_3$ to become equal to the virtual controller $\mathrm{u} \_1$ as shown in Fig. (5). As a result, the upper subsystem is began actuated by the designed sliding mode controller and that through the state $x_{-} \_$. After that, $x_{-} 3$ will regulate the sliding variable $s \_1$ asymptotically as shown in Fig. (6), and also can be seen in the error phase plot in Fig. (7). For implementing the virtual control in Eq. (15), it required to estimate the perturbation $\delta \_$. Figure (8), shows that the estimation to $\delta \_1$ follows the actual value, which also clarifies the performance of the SMPE. Additionally, the SMD was used to estimate the first and the second derivatives of the virtual controlleru_l. The result of the SMD is shown in Fig. (9), where the output of the SMD was used in obtaining the derivative to the error function for the lower subsystem $\left(\mathrm{e}_{-}^{\cdot} \mathrm{m}=\mathrm{x}_{-} 4-\mathrm{u}_{-}^{\cdot} \mathrm{l}\right)$. To this end, the first subsystem position $\mathrm{x} \_1$ tracks the desired position $\mathrm{x} \_1 \mathrm{~d}$ as shown in Fig. (10), where the proposed controller needs to less than $0.3 \mathrm{sec}$ to make $\mathrm{x} \_1$ follows the desired position and to be very closed to it after that where the error bound is less than $2 \times \llbracket 10 \rrbracket^{\wedge}(-4)$. Additionally, a small control effort, which is represented by the torque inputT_m $(t)$, was required for the tracking process as is demonstrated in Fig. (11). The plotted result in this figure is smooth due to using (arctan) function instead of the signum function; this leads to eliminate the chattering, which it the undesirable behavior in SMC.

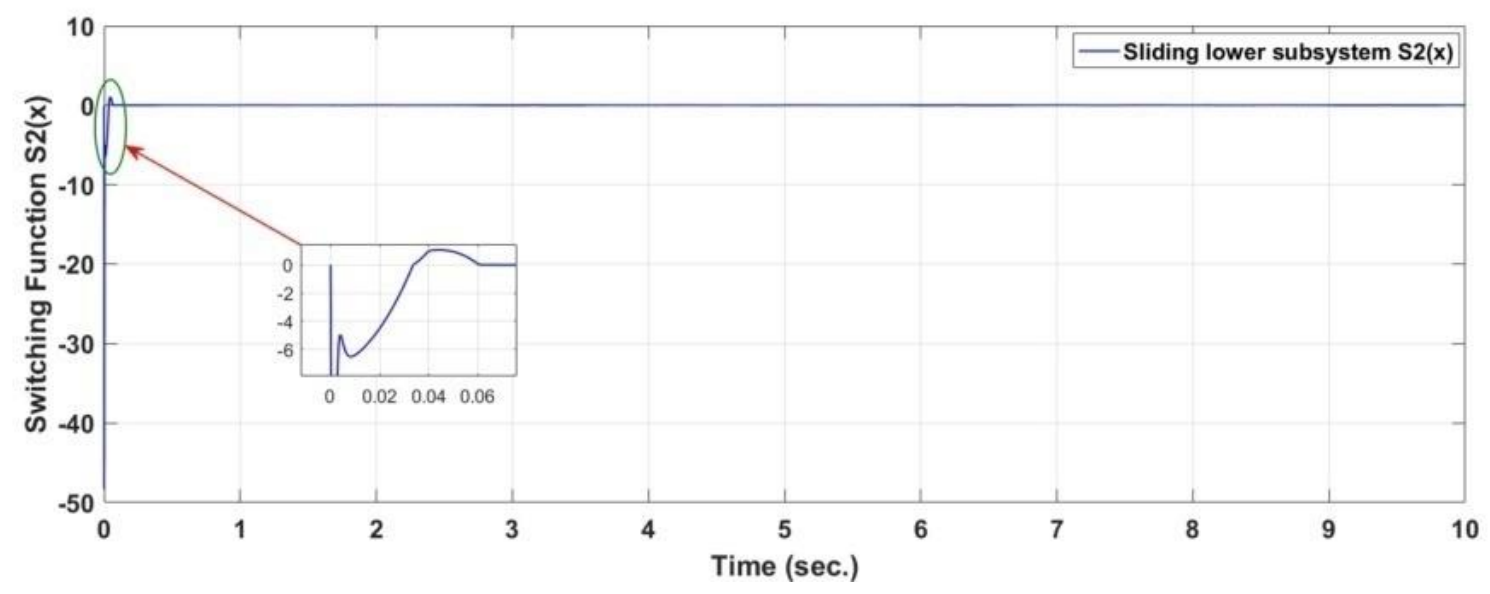

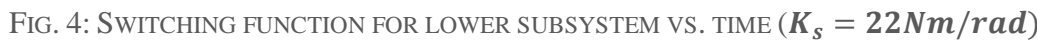

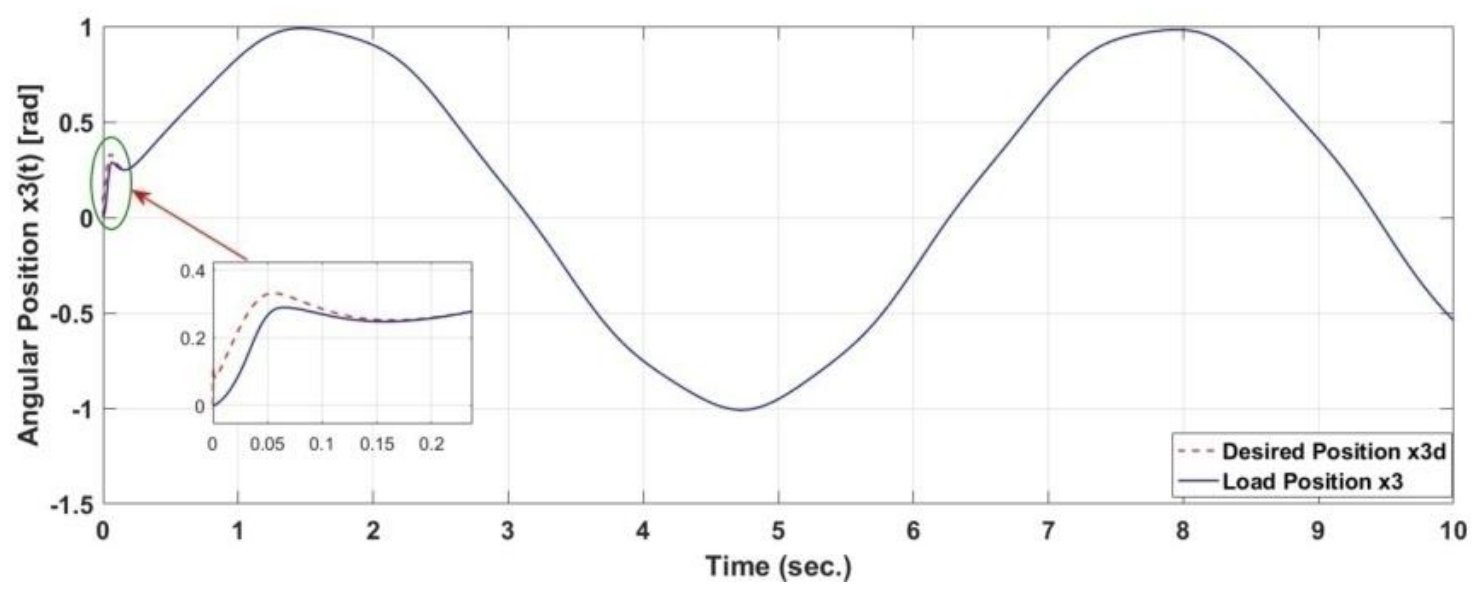

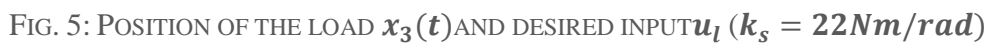




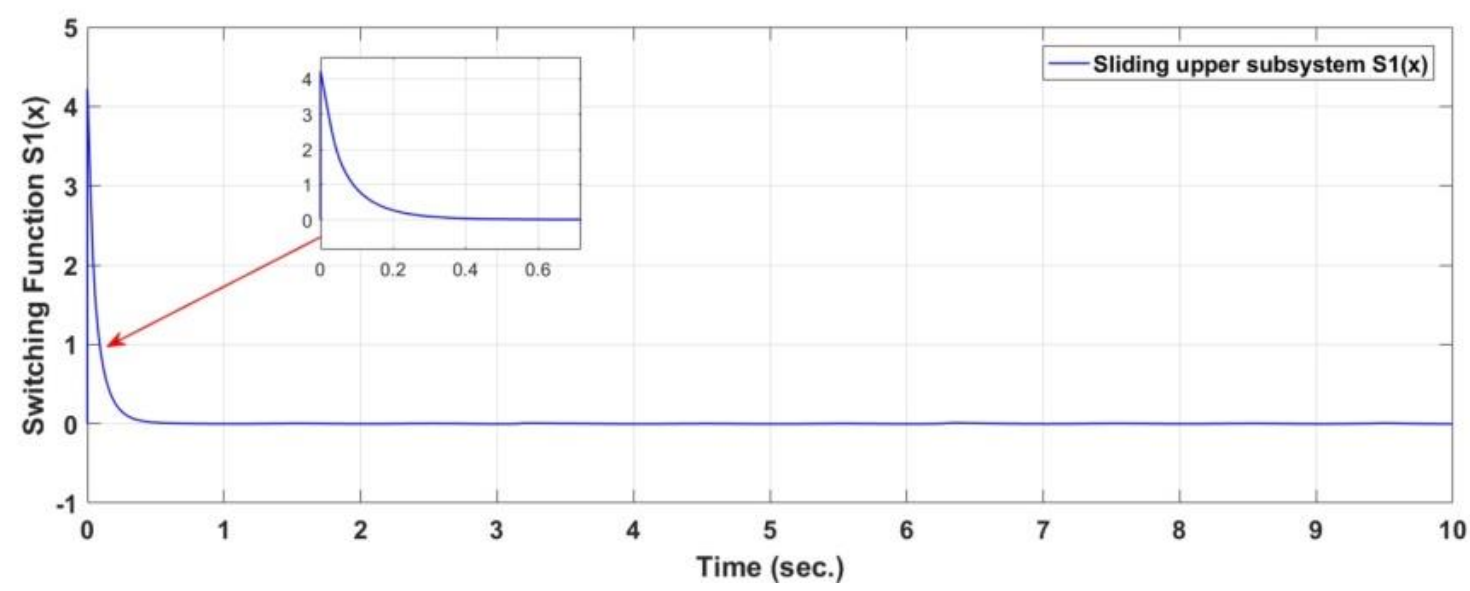

FIG. 6: SWITCHING FUNCTION FOR UPPER SUBSYSTEM VS. TIME $\left(\boldsymbol{k}_{\boldsymbol{s}}=\mathbf{2 2} \mathbf{N m} / \mathbf{r a d}\right)$

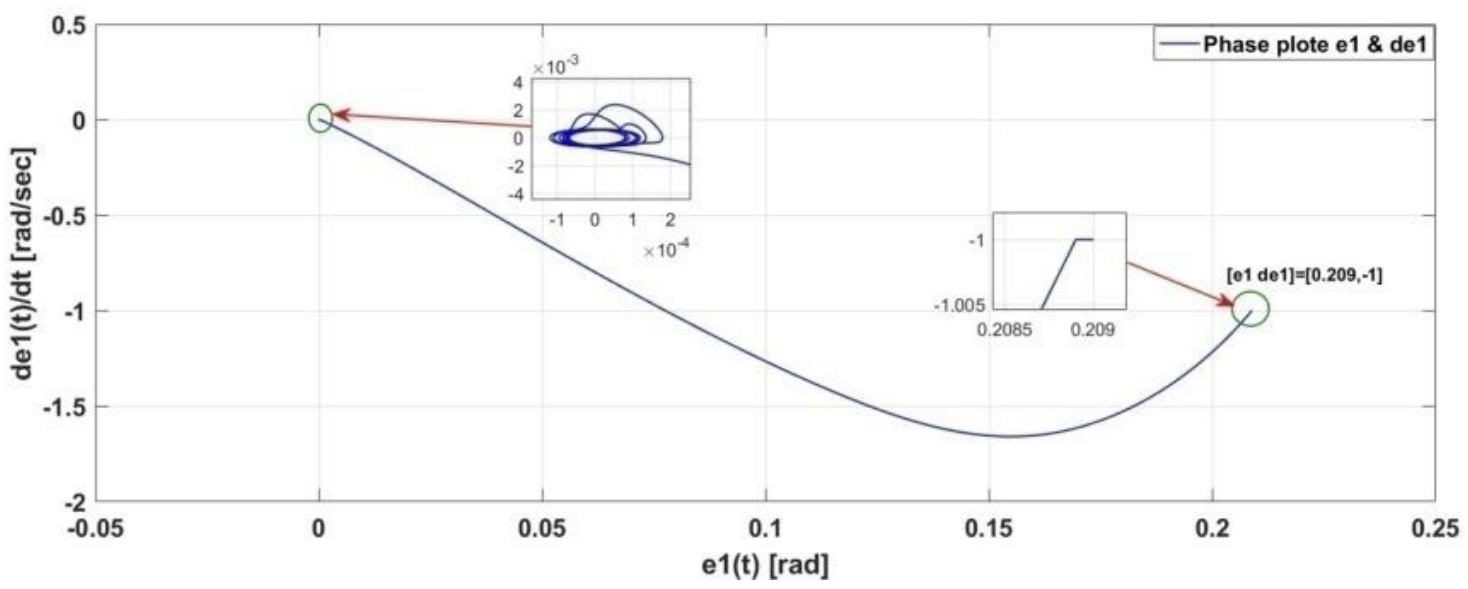

FIG. 7: THE ERROR PHASE PLOT $\left(\boldsymbol{e}_{1}\right.$ and $\left.\dot{e}_{1}\right),\left(\boldsymbol{k}_{\boldsymbol{s}}=\mathbf{2 2} \mathbf{N m} / \mathbf{r a d}\right)$

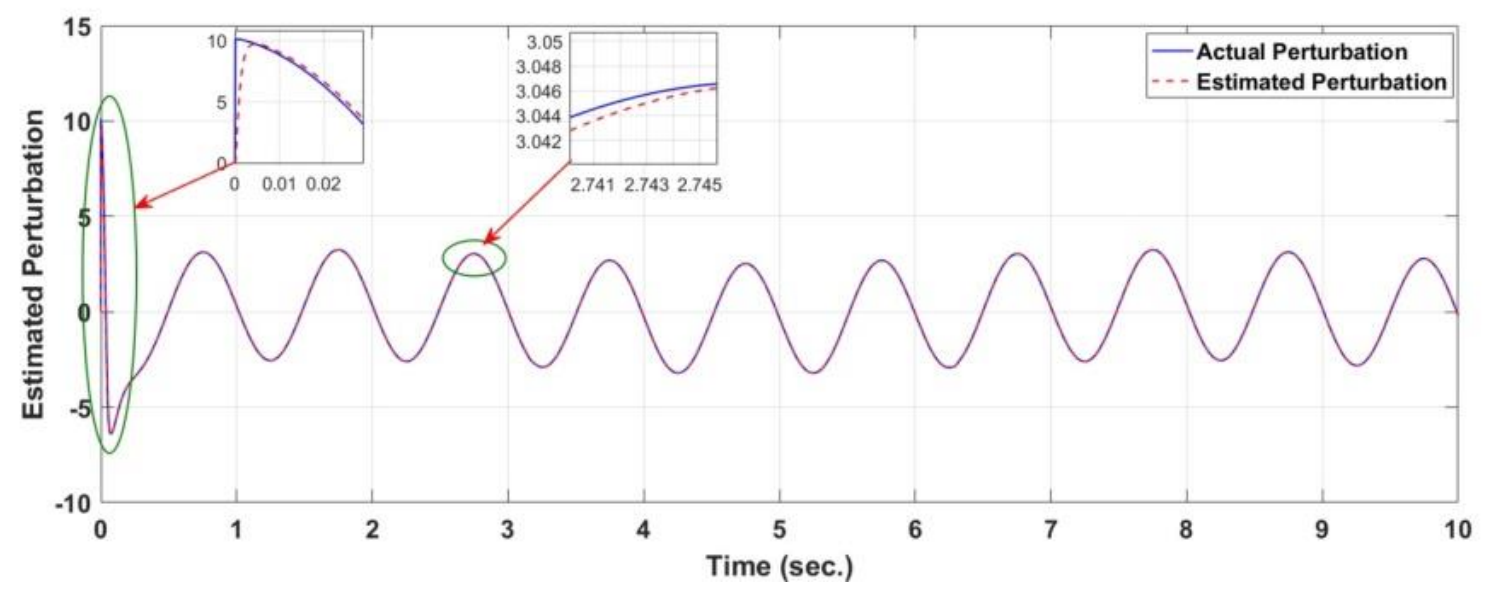

Fig. 8: Actual ANd Estimated Perturbation $(\boldsymbol{\delta a n d} \widehat{\boldsymbol{\delta}}),\left(\boldsymbol{k}_{\boldsymbol{s}}=\mathbf{2 2} \boldsymbol{N m} / \mathbf{r a d}\right)$ 


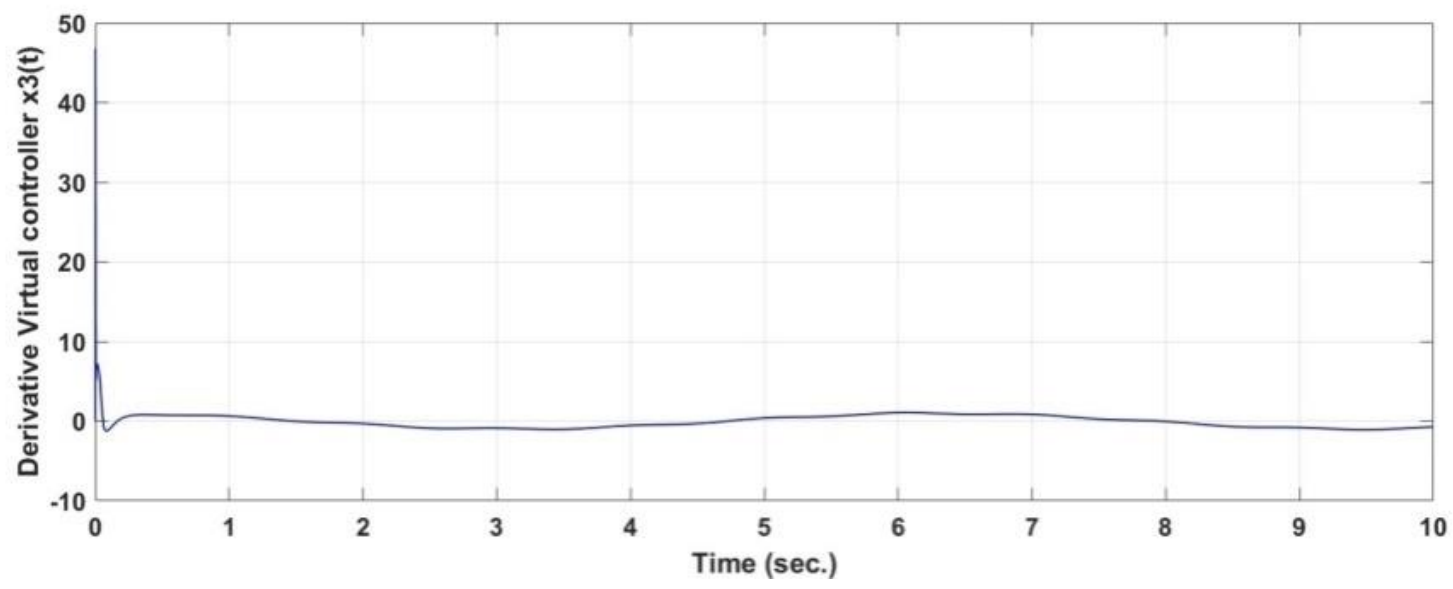

FIG. 9: Estimated DeRiVATIVE OF $u_{l}\left(\boldsymbol{k}_{\boldsymbol{s}}=\mathbf{2 2} \mathbf{N m} / \mathbf{r a d}\right)$

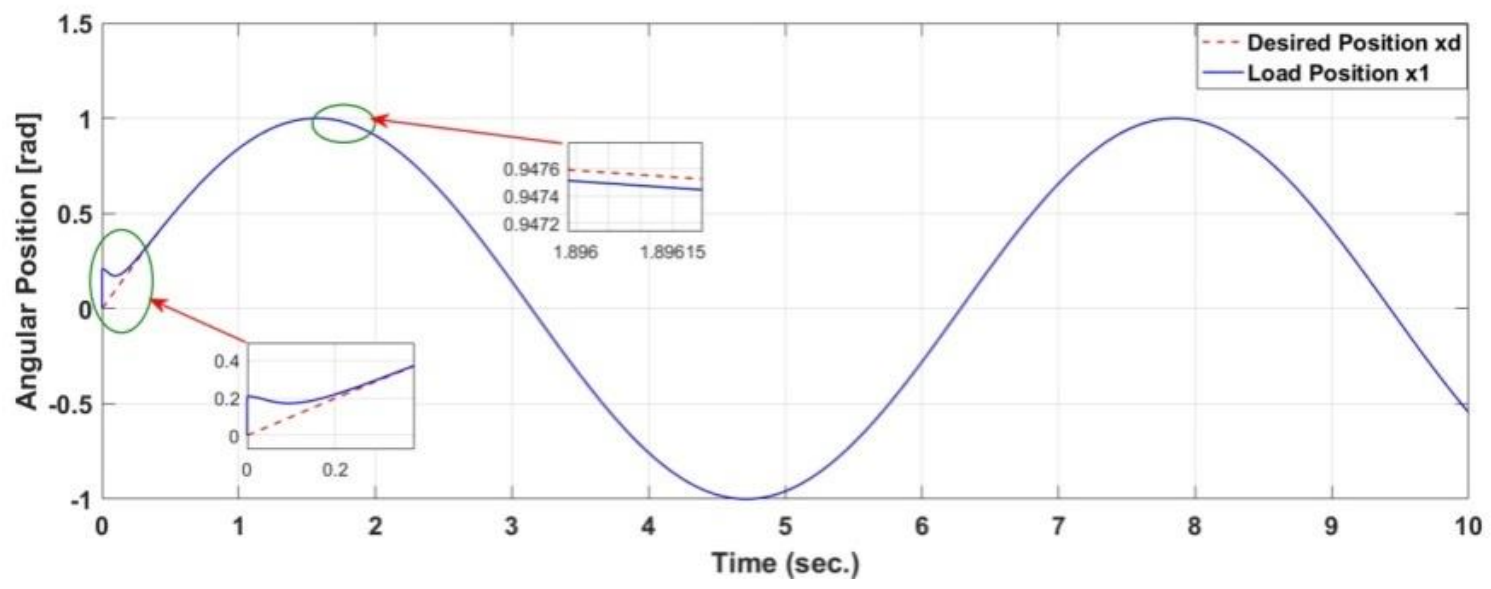

FIG. 10: POSITION OF THE SYSTEM $\boldsymbol{x}_{\mathbf{1}}(\boldsymbol{t})$ AND DESIRED POAITION $\left(\boldsymbol{k}_{\boldsymbol{s}}=\mathbf{2 2} \mathbf{N m} / \mathbf{r a d}\right)$

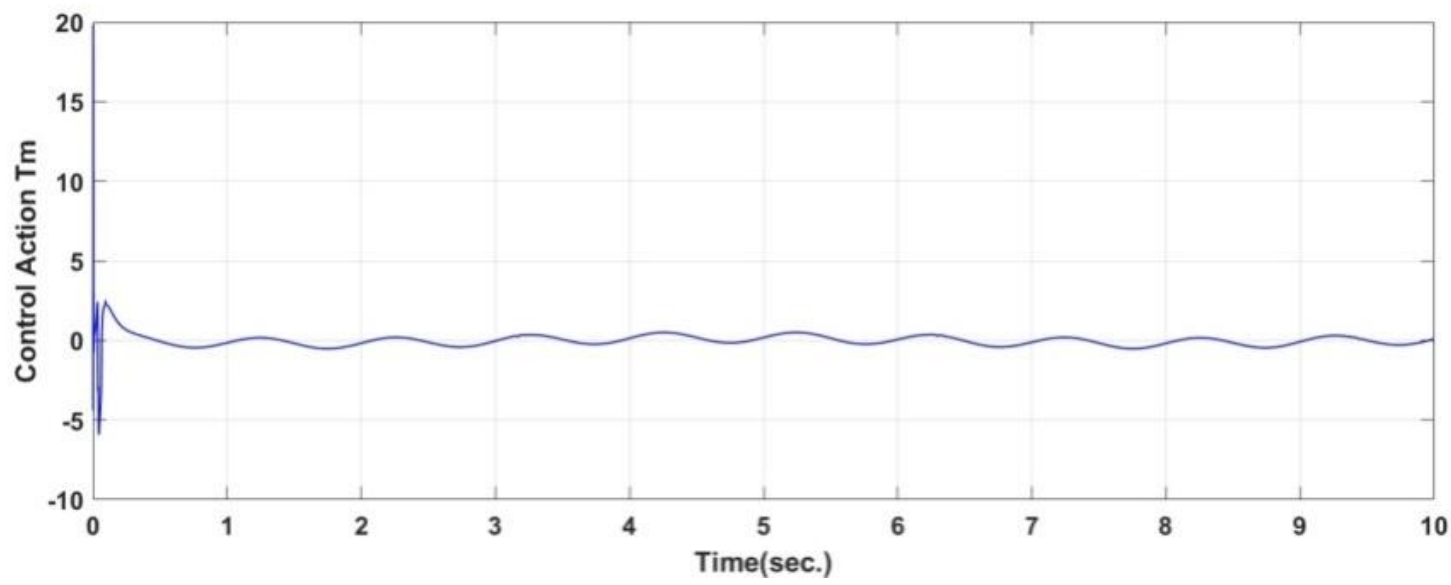

Fig. 11: CONTROL ACTION $\boldsymbol{T}_{\boldsymbol{m}}(\boldsymbol{t})$ vS. TIME

The ability and the robustness of the proposed controller are tested for the case where $K_{s}=26,36$, and for the same desired reference position. The simulation results are plotted in Figs. $(12,13,14$, and $15)$ for the tracking position of $x_{1}$ and perturbation estimation $\hat{\delta}$ respectively. 


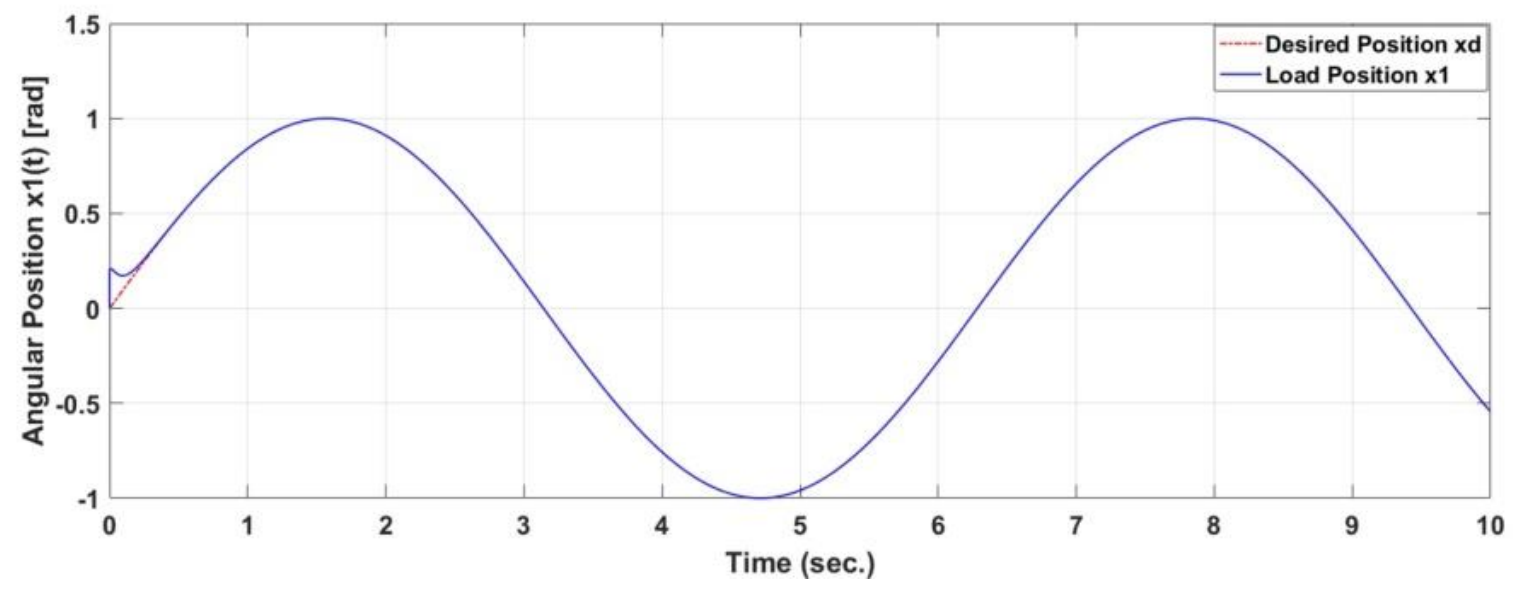

FIG. 12: POSITION OF THE SYSTEM $\boldsymbol{x}_{\mathbf{1}}(\boldsymbol{t})$ AND DESIRED POSITION $\left(\boldsymbol{k}_{\boldsymbol{s}}=\mathbf{2 6} \mathbf{N m} / \mathbf{r a d}\right)$

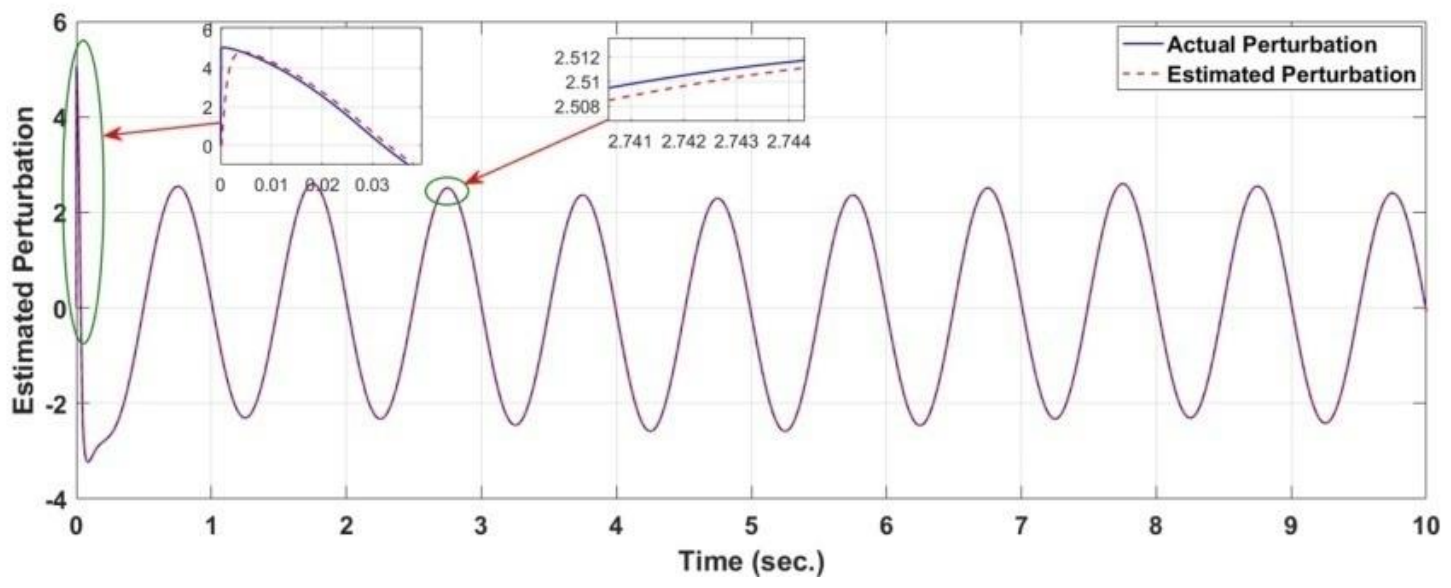

Fig. 13: Actual And Estimated Perturbation $(\boldsymbol{\delta a n d} \boldsymbol{\delta})\left(\boldsymbol{k}_{\boldsymbol{s}}=\mathbf{2 6} \mathbf{N m} / \mathbf{r a d}\right)$

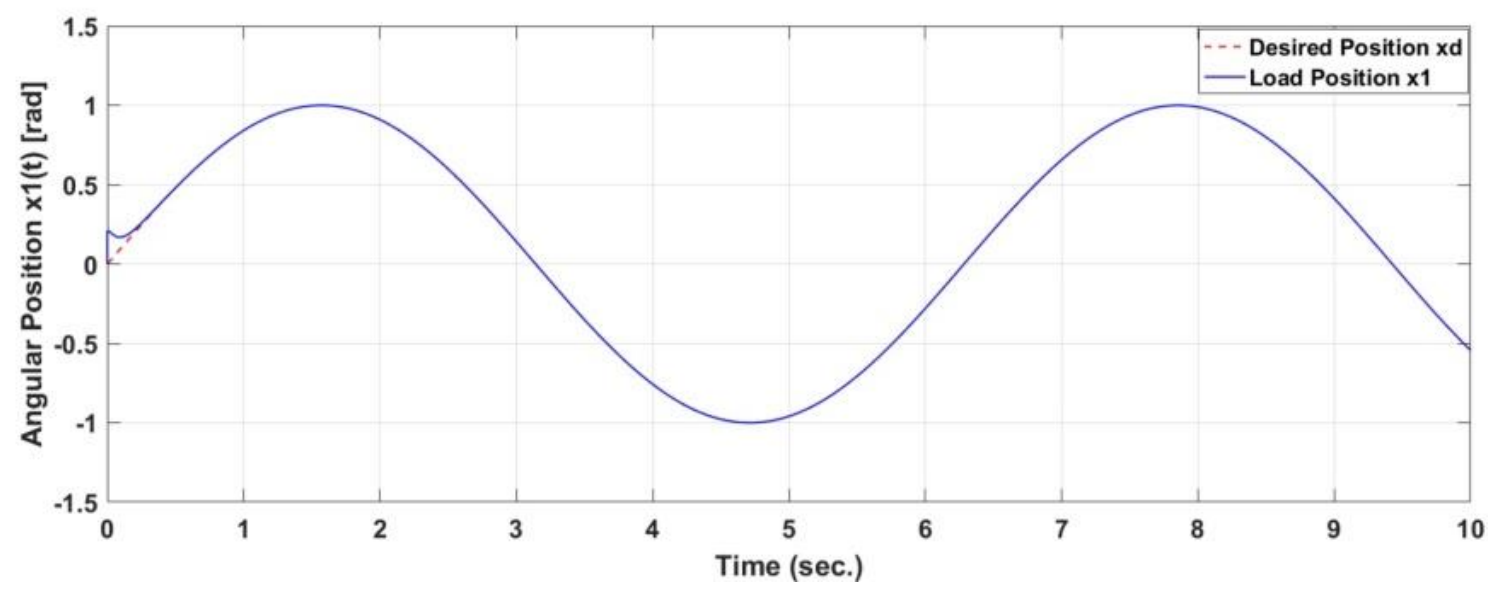

FIG. 14: POSITION OF THE SYSTEM $\boldsymbol{x}_{1}(\boldsymbol{t})$ AND DESIRED POSITION $\left(\boldsymbol{k}_{\boldsymbol{s}}=\mathbf{3 6} \mathbf{N m} / \mathbf{r a d}\right)$ 


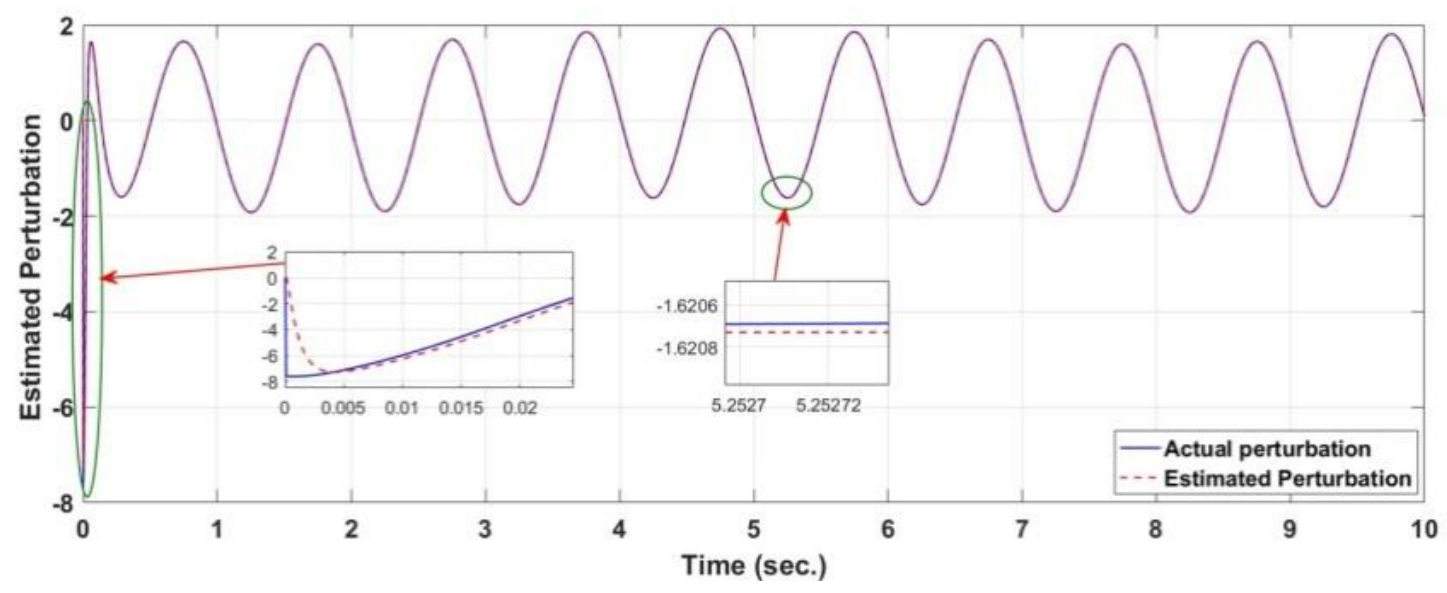

Fig. 15: Actual and Estimated Perturbation $(\boldsymbol{\delta a n d} \delta)\left(\boldsymbol{k}_{\boldsymbol{s}}=\mathbf{3 6} \mathbf{N m} / \mathbf{r a d}\right)$

The ability of the proposed sliding mode controller is again tested for the piecewise constant desired position with $K_{S}=22$. Figure (16) show the ability of the SMC in forcing $x_{1}$ to track the desired position.

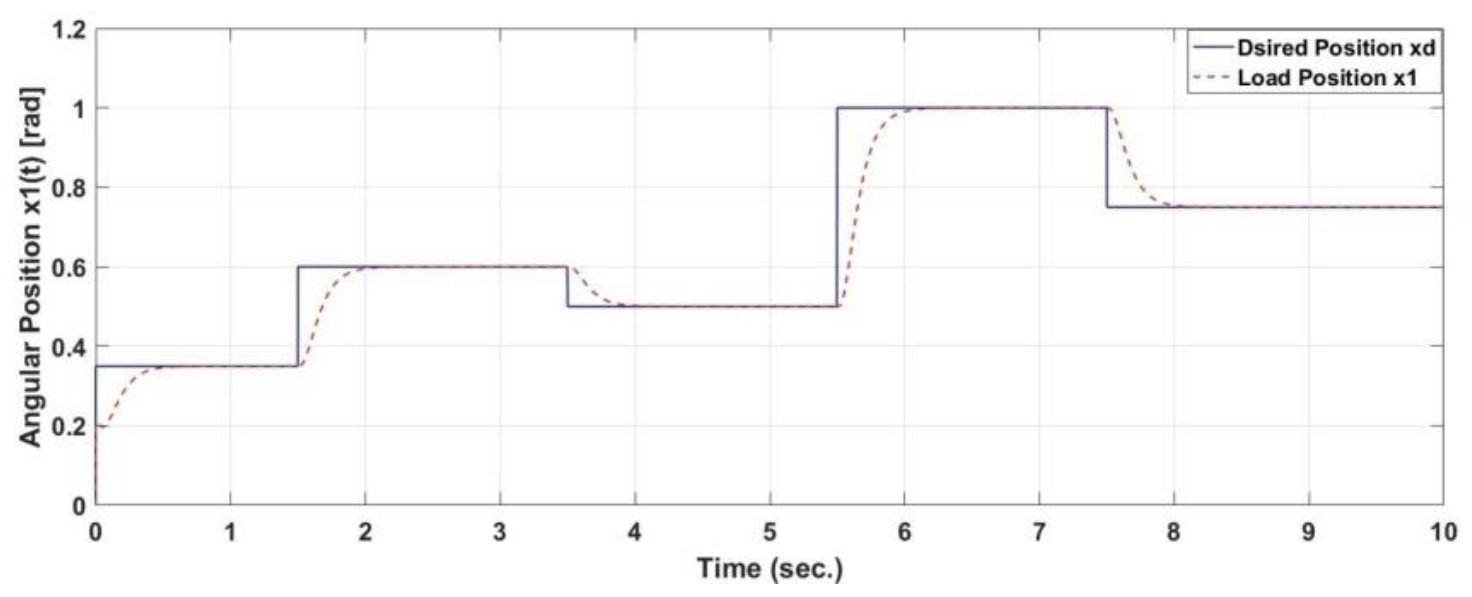

FIG. 16: POSITION OF THE SYSTEM $\boldsymbol{x}_{\mathbf{1}}(\boldsymbol{t})$ AND PIECEWISE CONSTANT DESIRED POSITION $\left(\boldsymbol{k}_{\boldsymbol{s}}=\mathbf{2 2} \boldsymbol{N \boldsymbol { m }} / \mathbf{r} \boldsymbol{a d}\right)$

\section{CONCLUSIONS}

In this paper, a sliding mode control for two mass systems connected by a flexible joint was proposed. Results exhibit that the proposed control method improves the performance of systems compared to conventional control methods.

The proposed scheme consists of separating the system into upper and lower subsystems, with estimating the perturbation $\delta \_1$ for the upper subsystem via SMPE. This step makes the desired position for the lower subsystem a differentiable function. The desired position was taken as a virtual controller to the upper subsystem. The sliding mode controllers for each subsystem were designed and their stability was proved using Lyapunov functions. The connection between the two subsystem controller was then made using the backstepping approach. The backstepping approach enables us to design a robust controller for the load mass using the electromagnetic torque T_m. In addition, the present work used the sliding mode perturbation estimator and differentiator (SMPE and SMD) to estimate the perturbation $\left(\delta \_1\right)^{\wedge}$ and the first and second derivative of the virtual controller $u \_1$.

The numerical simulation results demonstrated first the robustness and effectiveness of the proposed controller for the two mass system with bounded uncertainty in system parameters and in the 
presence of external disturbance. Secondly, the simulation results show high precision and fast-tracking for the load position to the desired reference for different shaft stiffness and desired references. Finally, the control action response is smooth because of using the arctan approximation function to the signum function, in addition, the chattering is eliminated with smaller control efforts by $\mathrm{T} \_\mathrm{m}$.

\section{REFERENCES}

[1] M. F. M. Yakub, A. Qadir, and B. Aminudin, "Comparative study on control method for two-mass systems," International Journal on Advanced Science, Engineering and Information Technology, vol. 2, pp. 261-266, 2012.

[2] G. Shahgholian, J. Faiz, and P. Shafaghi, Analysis and Simulation of Speed Control for Two-Mass Resonant System, 2010 .

[3] K. Sato, K. Nakamoto, and A. Shimokohbe, "Practical control of precision positioning mechanism with friction," Precision Engineering, vol. 28, pp. 426-434, 2004.

[4] G. Shahgholian, "Modeling and simulation of a two-mass resonant system with speed controller," International Journal of Information and Electronics Engineering, vol. 3, p. 448, 2013.

[5] M. Shahrokhi and A. Zomorrodi, "Comparison of PID controller tuning methods," Department of Chemical \& Petroleum Engineering Sharif University of Technology, pp. 1-2, 2013.

[6] E. Sariyildiz, H. Yu, and K. Ohnishi, "A practical tuning method for the robust PID controller with velocity feedback," Machines, vol. 3, pp. 208-222, 2015.

[7] M. Ruderman, W. Maebashi, and M. Iwasaki, "Semi-dual loop control of two-mass actuator system using Luenberger state observer," in Industrial Electronics Society, IECON 2013-39th Annual Conference of the IEEE, 2013, pp. 65636568.

[8] J. KABZIŃSKI and P. MOSIOŁEK, "Adaptive control of two-mass drive system with nonlinear stiffness," Przegląd Elektrotechniczny, vol. 94, 2018.

[9] S. Sharma and A. Gangopadhyay, "Modelling, Simulation and Speed Control of the Two-Mass Drive System."

[10] J. S. Bang, H. Shim, S. K. Park, and J. H. Seo, "Robust tracking and vibration suppression for a two-inertia system by combining backstepping approach with disturbance observer," IEEE transactions on industrial electronics, vol. 57, pp. 3197-3206, 2010.

[11] Y. Bin, M. Al-Majed, and M. Tomizuka, "High-performance robust motion control of machine tools: an adaptive robust control approach and comparative experiments," IEEE/ASME Transactions on Mechatronics, vol. 2, pp. 6376, 1997.

[12] S. Doo-Jin and H. Uk-Youl, "Robust motion controller design for servo system with 2 mass characteristics," in 6th International Workshop on Advanced Motion Control. Proceedings (Cat. No.00TH8494), 2000, pp. 423-426.

[13] I. Scholing and B. Orlik, "Control of a nonlinear two-mass system with uncertain parameters and unknown states," in Conference Record of the 2000 IEEE Industry Applications Conference. Thirty-Fifth IAS Annual Meeting and World Conference on Industrial Applications of Electrical Energy (Cat. No.00CH37129), 2000, pp. 1096-1103 vol.2.

[14] K. Sugiura and Y. Hori, Vibration suppression in 2-and 3-mass system based on the feedback of imperfect derivative of the estimated torsional torque vol. 43, 1996.

[15] P. Dróżdż and K. Szabat, "Filtered integral sliding mode control in a two-mass drive system," Power Electronics and Drives, vol. 2, pp. 121-134, 2017.

[16] P. Korondi, H. Hashimoto, and V. Utkin, "Sliding mode design for two mass system based on reduced order model," IFAC Proceedings Volumes, vol. 30, pp. 303-308, 1997.

[17] J. Fu, L. Wang, Y. Du, and J. Zhang, "A robust sliding mode control for nonlinear system with adjustable chattering phenomenon," in 2016 14th International Workshop on Variable Structure Systems (VSS), 2016, pp. 34-38.

[18] H. Wang, Z. Man, H. Kong, Y. Zhao, M. Yu, Z. Cao, et al., "Design and Implementation of Adaptive Terminal Sliding-Mode Control on a Steer-by-Wire Equipped Road Vehicle," IEEE Transactions on Industrial Electronics, vol. 63, pp. 5774-5785, 2016.

[19] F. Gong and X. Ren, "Extended State Observer Based Adaptive Integral Sliding Mode Control for Two Inertia System," in 2015 7th International Conference on Intelligent Human-Machine Systems and Cybernetics, 2015, pp. 483-486.

[20] B. Torchani, A. Sellami, and G. Garcia, "Saturateci sliding mode control for variable speed wind turbine," in 2014 5th International Renewable Energy Congress (IREC), 2014, pp. 1-5.

[21] T. Orlowska-Kowalska, M. Kaminski, and K. Szabat, "Implementation of a Sliding-Mode Controller With an Integral Function and Fuzzy Gain Value for the Electrical Drive With an Elastic Joint," IEEE Transactions on Industrial Electronics, vol. 57, pp. 1309-1317, 2010.

[22] S. Brock, "Hybrid P-PI sliding mode position and speed controller for variable inertia drive," Przeglqd Elektrotechniczny (Electrical Review), vol. 90, pp. 29-34, 2014.

[23] J. Liu and X. Wang, Advanced sliding mode control for mechanical systems: Springer, 2012. 
[24] S. Poorinezhad and S. M. RakhtAla, "Chattering analysis of second order sliding mode algorithms for linear plants with disturbance," in 2015 2nd International Conference on Knowledge-Based Engineering and Innovation (KBEI), 2015, pp. 101-105.

[25] W. Ali, "Speed control of electrical drives with resonant loads," 2011.

[26] G. Shahgholian, A. Etesami, M. R. Yousefi, and F. M. Tehrani, "Development of state space model and control design of two-mass system using standard forms," in Communication Software and Networks (ICCSN), 2011 IEEE 3rd International Conference on, 2011, pp. 342-346.

[27] M. Nordin and P.-O. Gutman, "Controlling mechanical systems with backlash-a survey," Automatica, vol. 38, pp. 1633-1649, 2002.

[28] M. Jankovic, D. Fontaine, and P. V. KokotoviC, "TORA example: cascade-and passivity-based control designs," IEEE Transactions on Control Systems Technology, vol. 4, pp. 292-297, 1996.

[29] S. A. AL-Samarraie, "A Chattering Free Sliding Mode Observer with Application to DC Motor Speed Control," in 2018 Third Scientific Conference of Electrical Engineering (SCEE), 2018, pp. 259-264. 